\title{
Down regulation of Thrombospondin2 predicts poor prognosis in patients with gastric cancer
}

\author{
Ruochuan Sun ${ }^{1 \dagger}$, Jifeng $\mathrm{Wu}^{2 \dagger}$, Yuanyuan Chen ${ }^{3 \dagger}$, Mingdian Lu', Shangxin Zhang ${ }^{1}$, Daru Lu ${ }^{3^{*}}$ and Yongxiang $\mathrm{Li}^{\mathrm{1}^{*}}$
}

\begin{abstract}
Background: Thrombospondins (THBSs) are a family of multidomain and secreted matricellular $\mathrm{Ca}^{2+}$-binding glycoproteins which has at least five members encoded by independent genes. As a THBSs family member, Thrombospondin2 (THBS2) has been reported to regulate angiogenesis. Nevertheless, the functions and clinical significance of THBS2 still remains unclear in gastric cancer.
\end{abstract}

Methods: The mRNA and protein expression levels of THBS2 were assessed in 14 paired of gastric cancer specimens and corresponding normal mucosas using quantitative real-time PCR and western blot analysis. Immunohistochemistry of THBS2 and CD34 on population-based tissue microarrays consisting of 129 gastric cancer cases were used to evaluate the prognostic significance of THBS2 and microvessel density (MVD) of each sample. Survival analyses were performed by Kaplan-Meier method and Cox's proportional hazards model. Colony formation assay, endothelial cell tube formation assay, cell migration assay and apoptosis analysis in MKN-45 and SGC-7901 cell lines were carried out to evaluate the effects of THBS2 on gastric cancer in vitro.

Results: $85.71 \%$ (12 of 14) gastric cancer tissues expressed remarkably lower THBS2 in both mRNA and protein levels than the corresponding normal controls. Consistently, tissue microarray (TMA) results showed THBS2 levels were also inhibited in gastric cancer tissues compared with the normal controls. Moreover, we observed that patients with higher levels of THBS2 were significantly correlated with more favourable prognosis while decreased THBS2 expression were associated with poorer histological grades of gastric cancer. Additionally, our in vitro experiments further demonstrated that overexpression of THBS2 could impede both the proliferation rate and the tube formation of Human umbilical vein endothelial cells (HUVECS) in MKN-45 and SGC-7901 cell lines.

Conclusion: Our study suggests THBS2 is aberrantly expressed in gastric cancer and plays a critical role in cancer progression, which can be a potential prognosis predictor of gastric cancer.

Keywords: THBS2, Gastric cancer, Angiogenesis, Prognostic biomarker

\section{Introduction}

Gastric cancer is a highly aggressive and lethal malignancy. A total of 952,000 new stomach cancer cases and 723,000 deaths were estimated to have occurred in 2012, accounting for $6.8 \%$ of the total cases and $8.8 \%$ of total deaths. Moreover, Both new cases and deaths of gastric cancer in China, ranked 1st globally, accounting for over $40 \%$

\footnotetext{
* Correspondence: darulu@hotmail.com; yongxiangli_1@hotmail.com ${ }^{\dagger}$ Equal contributors

${ }^{3}$ State Key Laboratory of Genetic Engineering, Fudan-VARI Genetic Epidemiology Center and MOE Key Laboratory of Contemporary Anthropology, Fudan University, Shanghai, China

'The Eighth Department of General Surgery, Hefei, China

Full list of author information is available at the end of the article
}

of that in the world [1]. Therefore great concerns are raised for the researches of gastric cancer.

Thrombospondins (THBSs) are a family of multidomain and matricellular $\mathrm{Ca}^{2+}$-binding glycoproteins secreted by stromal fibroblasts, endothelial cells and immune cells [2]. They have at least five members encoded by independent genes. By binding with numerous target proteins, they participate in diverse biologic processes such as angiogenesis, cell motility, apoptosis, cytoskeletal organization, and serve as interaction platforms in the extracellular matrix (ECM) [3,4]. Notably, THBS1 and THBS2 are special in this family for their type I repeats and both of them are mainly shown as inhibitors of angiogenesis [5,6], one key part of cancer research [7-9]. Microvessel density (MVD) 
is a widely used parameter to estimate the degree of angiogenesis in tumours with CD34 being the microvessel maker in gastric cancer [10]. Based on the previous findings [2], we put forward a hypothesis in our study that it could also affect the angiogenesis in gastric cancer.

Besides angiogenesis, THBS2 has been reported to interact with multiple cell receptors, growth factors and ECM proteins as well as regulate apoptosis, cell proliferation and adhesion [11]. In cancer researches, increasing attentions have been focused on THBS2. Tokunaga et al. [12] found that THBS2 expressed in patients with colon cancer exhibited a significant lower risk of hepatic metastases and tumour vascularity compared with the patients whose tumours were THBS2 deficiency. Furthermore, De Fraipont et al. [13] demonstrated that THBS2 was significantly correlated with clinical status and outcome, and for most tumours, there was an inverse correlation between the THBS2 expression level and the degree of their malignancy. In addition, THBS2 also played a key role in breast cancer [14], myeloma [15], malignant melanoma [16], prostate cancer [17] and pulmonary adenocarcinoma $[18,19]$. In gastric cancer, other members of THBSs, THBS1 [20] and THBS4 [21] could be as a prognostic biomarker or a powerful marker for diffuse-type gastric adenocarcinomas. However, the detailed function of THBS2 in gastric cancer and its implications for clinical diagnose still remain dismal. Thus, we attempted to unveil the clinical significance of THBS2 and its effect in gastric cancer.

To verify our aforementioned hypothesis, we examined the THBS2 expression levels in human gastric cancer tissues and corresponding normal tissues and then explored the possible correlations between the expression of THBS2 and clinicopathological features, clinical prognosis and the MVD counting in patients with gastric cancer. In addition, colony formation assay, endothelial cell tube formation assay, cell migration assay and apoptosis analysis were carried out in MKN-45 and SGC-7901 cell lines to explore the in vitro effect of THBS2 in gastric cancer cells.

\section{Results}

\section{Patient characteristics and clinical outcomes}

In the present study, we enrolled 129 eligible patients, which consisted of 101 males and 28 females. The age of the patients ranged from 29 to 80 years (y) with a median age of $61 y$. All the clinicopathological characteristics are summarized in Table 1 . The median overall survival (OS) of the patients was 57 months, and mean OS was 44.01 [95\% confidence interval (CI) 39.78-49.24 months].

\section{THBS2 is down-regulated in gastric cancer}

In order to determine the expression levels of THBS2 in gastric cancer, we first evaluated the mRNA expression levels of THBS2 in gastric cancer by quantitative real-time in the second cohort. This cohort of samples, mentioned in Methods, included 14 human gastric cancer and the corresponding normal tissues. As shown in Figure 1A, THBS2 levels were markedly lower in $85.7 \%$ (12 of 14) of the gastric cancer tissues than its normal controls, while the remaining two pairs of the samples exhibited the opposite. Then, we detected the protein expression levels of THBS2 via western blot in the same cohort. As show in Figure $1 \mathrm{~B}$ and $\mathrm{C}$, we observed that THBS2 protein expression levels were decreased in $85.7 \%$ (12 of 14) of the tumour samples compared with its corresponding control, while sample 5 and 11 displayed inversely. To confirm this finding, we further performed a tissue microarray (TMA) and assessed the protein expression levels of THBS2 according to the immunoreactivity score (IRS) of each sample. We found THBS2 proteins were mainly expressed in the cytoplasms of gastric cells (Figure 2A), and in accordance with the results of western blot, the levels of THBS2 were significantly inhibited in gastric cancer tissues compared with the normal controls (Figure $2 \mathrm{~B}, \mathrm{P}<0.05$ ). Taken together, our results demonstrates that THBS2 is down-regulated in gastric cancer in both mRNA and protein levels.

\section{THBS2 expression levels are inverse correlated with histological grades of gastric cancer}

To further clarify the clinical importance of THBS2, we analysed the relationship between THBS2 protein expression and clinical features including age, gender, histological grade, tumour location, depth of invasion, lymph node metastasis and TNM stage of gastric cancer patients in THBS2-positive and negative groups. As shown in Table 1, we found a significant inverse correlation with the histological grades of gastric cancer $(P<0.01)$. The histological grades of patients in THBS2-positive group were more likely to be well and moderate, whereas patients in THBS2-negative group tended to be poor and other. However, we failed to discover any significance statistically between the expression levels of THBS2 and other clinical parameters. Collectively, our findings suggest that THBS2 is inverse correlated with histological grade of gastric cancer.

\section{THBS2 expression levels are inverse correlated with MVD in gastric cancer}

Previous reports implied THBS2 could regulate tumour angiogenesis [6], yet none was reported in gastric cancer. Hence, we asked whether there were any correlations between MVD and THBS2 expression levels as well as other clinical parameters in our clinical samples. The MVD in 129 gastric cancer specimens ranged from 0 to 120 , with the median of 40 and mean of $48.12 \pm 28.99$ (mean \pm SD) according to the immunoreactivity of CD34 
Table 1 Association among clinicopathological variables and THBS2 expression and overall survival of gastric cancer patients

\begin{tabular}{|c|c|c|c|c|c|c|}
\hline \multirow[t]{2}{*}{ Variables } & \multirow[t]{2}{*}{ Negative } & \multirow[t]{2}{*}{ Positive } & \multirow[t]{2}{*}{ Total No. } & \multirow[t]{2}{*}{$P$ value $^{\mathrm{a}}$} & \multicolumn{2}{|c|}{ Overall survival OS } \\
\hline & & & & & Log-Rank $P^{b}$ & $\mathrm{HR}(95 \% \mathrm{Cl})$ \\
\hline & No.(\%) & No.(\%) & & & & \\
\hline Age (y) & & & & 0.112 & 0.743 & \\
\hline$<61$ & $24(38.1)$ & 39(61.9) & 63 & & & 1 (reference) \\
\hline$\geq 61$ & $35(53.0)$ & $31(47.0)$ & 66 & & & $1.09(0.67-1.77)$ \\
\hline Gender & & & & 0.831 & 0.405 & \\
\hline Male & $47(46.5)$ & $54(53.5)$ & 101 & & & 1 (reference) \\
\hline Female & $12(42.9)$ & $16(57.1)$ & 28 & & & $0.76(0.40-1.45)$ \\
\hline Histological grade & & & & 0.005 & 0.011 & \\
\hline Well and moderate & $24(33.8)$ & $47(66.2)$ & 71 & & & 1 (reference) \\
\hline Poor and other & $35(60.3)$ & 23(39.7) & 58 & & & $1.89(1.16-3.09)$ \\
\hline Tumor location & & & & 0.419 & 0.204 & \\
\hline Upper & $27(40.3)$ & $40(59.7)$ & 67 & & & 1 (reference) \\
\hline Middle & $15(53.6)$ & 13(46.4) & 28 & & & $1.66(0.86-3.18)$ \\
\hline Lower & $17(50.0)$ & $17(50.0)$ & 34 & & & $1.90(0.90-4.01)$ \\
\hline Depth of invasion & & & & 0.271 & 0.001 & \\
\hline $\mathrm{T} 1-\mathrm{T} 2$ & $9(34.6)$ & $17(65.4)$ & 26 & & & 1 (reference) \\
\hline T3-T4 & $50(48.5)$ & 53(51.5) & 103 & & & $11.60(2.83-47.45)$ \\
\hline Lymph node metastasis & & & & 0.454 & $<0.001$ & \\
\hline Absent & $17(40.5)$ & $25(59.5)$ & 42 & & & 1 (reference) \\
\hline Present & $42(48.3)$ & $45(51.7)$ & 87 & & & $5.16(2.46-10.84)$ \\
\hline TNM stage & & & & 0.283 & $<0.001$ & \\
\hline$|-| \mid$ & $21(39.6)$ & $32(60.4)$ & 53 & & & 1 (reference) \\
\hline III-IV & $38(50.0)$ & $38(50.0)$ & 76 & & & $7.14(3.52-14.49)$ \\
\hline
\end{tabular}

Bold value is statistically significant at $P<0.05$, HR hazard ratio.

a $P$ value of clinicopathological variables and THBS2 expression.

${ }^{b}, P$ value of association between clinicopathological variables and overall survival of gastric cancer patients.

in our TMA. As shown in Figure 2C, THBS2 was significantly correlated with MVD. The MVD in THBS2-negative group was much higher than that in THBS2-positive group $(P<0.001)$. However, we could not observe any statistic differences between MVD and other clinicopathologic features including clinical prognosis in our samples (data not shown). In conclusion, our discoveries demonstrate that THBS2 is inverse correlated with MVD in gastric cancer.

THBS2 is significantly associated with clinical prognosis of gastric cancer patients

To examine the relationship between THBS2 expression and the clinical prognosis of gastric cancer patients, we conducted survival analyses by univariate and multivariate Cox's proportional hazards regression model. As shown in Table 1, we found histological grade, depth of invasion, lymph node metastasis and TNM stage were statistically significant factors for OS in univariate analysis. However, since TNM stage also contains the information of depth of invasion and lymph node metastasis, we further performed multivariate survival analyses with adjustment for the histological grade and TNM stage. We noticed that TNM stage $(P<0.001)$ and THBS2 expression $(P<0.01)$ were both independent prognostic factors for the assessment of patient outcomes. Higher TNM stage was a risk factor for longer OS $[P<0.001$, HR (hazard ratio) $=7.23$, 95\% CI 3.55-14.69) and elevated expression of THBS2 was yet a favourable factor for longer OS $(P<0.01, \mathrm{HR}=0.51$, 95\% CI 0.31-0.85). Moreover, Kaplan-Meier survival analysis further confirmed that THBS2 expression was significantly correlated with clinical outcomes (Figure 3, $\mathrm{P}<0.01, \mathrm{n}=129)$. Patients with lower THBS2 expression displayed a significantly shorter OS [median 36 months, mean $40.07 \pm 3.65$ (mean \pm SE) months], whereas patients with higher THBS2 expression showed a favourable prognosis [median 59 months, mean $53.70 \pm 2.95$ (mean $\pm \mathrm{SE}$ ) months]. Together, our results demonstrate THBS2 is significantly associated with the clinical prognosis of gastric 

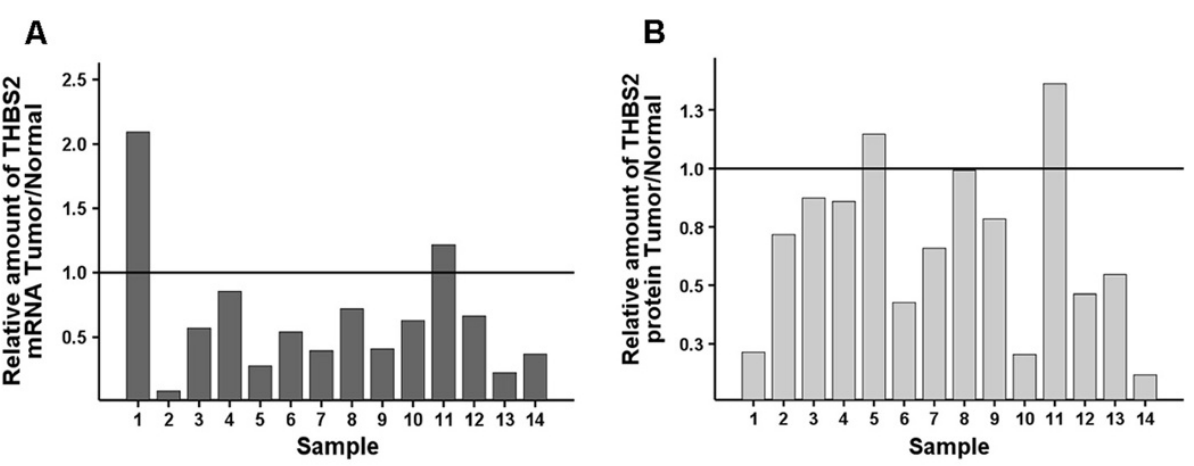

C
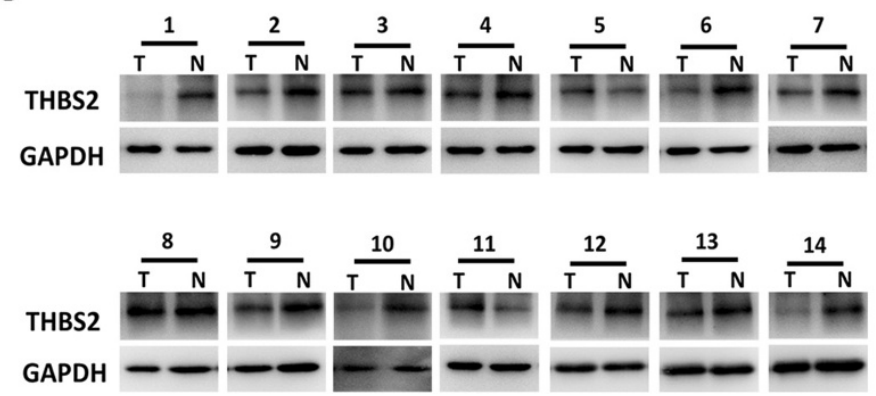

Figure 1 mRNA and protein expression level of THBS2 in 14 gastric cancer tissues and the corresponding normal tissue. (A) Relative mRNA expression of THBS2 was detected by quantitative real-time PCR. Expression of normal tissues were normalized to 1.0 as indicated. (B) The densitometry analysis results of the THBS2 bands were normalized to GAPDH using Image J. Expression of normal tissues were normalized to 1.0 as indicated. (C) Relative protein expression of THBS2 was estimated by Western blot assay.

cancer patients, which might become a prognostic marker for gastric cancer.

\section{Overexpression of THBS2 inhibits the growth of gastric cancer cells in vitro}

Because THBS2 was significantly down-regulated in gastric cancer, we inferred that THBS2 might inhibit growth, promote apoptosis and enhance the migration ability of gastric cancer cells. To verify our hypothesis, we first constructed one lentiviral vector to stable express THBS2 transcripts in gastric cancer cell lines. Altered expression of THBS2 in $293 \mathrm{~T}$ cells was confirmed by western blot analysis (Figure 4A). Then, we chose MKN-45 and SGC-7901 cell lines for our in vitro study because the mRNA expression levels of THBS2 were lower than others (data not shown). We then performed the colony formation assay to evaluate the effects of THBS2 on the growth of MKN-45 and SGC-7901 cells. As shown in Figure 4B, we found cells with THBS2 overexpression formed significantly fewer colonies on soft agar compared with those of control vector-infected cells $(P<0.01$ for $\mathrm{MKN}-45$ cells and $P<0.001$ for SGC-7901 cells, respectively). Moreover, we examined the apoptosis levels between the two groups in both cell lines and discovered that THBS2 promoted apoptosis in SGC-7901 cells (Figure 4F) but not in MKN-45 cells (Additional file 1: Figure S1A). And there were no significant differences between the two groups in SGC-7901 and MKN-45 cell lines in cell migration according to the transwell assays (Additional file 1: Figure S1B and C). In summary, our data support that THBS2 impedes the growth of gastric cancer cells in vitro possibly via the regulation of apoptosis.

\section{THBS2 suppresses gastric cancer angiogenesis in vitro}

THBS2 is known as an inhibitor of angiogenesis [2]. To provide evidences of THBS2 regulates the angiogenic phenotype of gastric cancer, endothelial cell tube formation assays were carried out. As shown in Figure 4E and D, in both MKN-45 and SGC-7901 cell lines, human umbilical vein endothelial cells (HUVECs) cultured with the medium from THBS2-overexpression gastric cancer cells showed significantly lower AngiogenicIndexCh1 than the negative control $(P<0.05$ for MKN-45 cells and $P<0.001$ for SGC7901 cells, respectively ). Collectively, our results imply that THBS2 suppresses the angiogenesis of gastric cancer cells in vitro.

\section{Discussion}

THBS2 is known as a natural potent inhibitor of angiogenesis and a modulator of the remodelling process $[22,23]$. However, none of the former researches discussed 

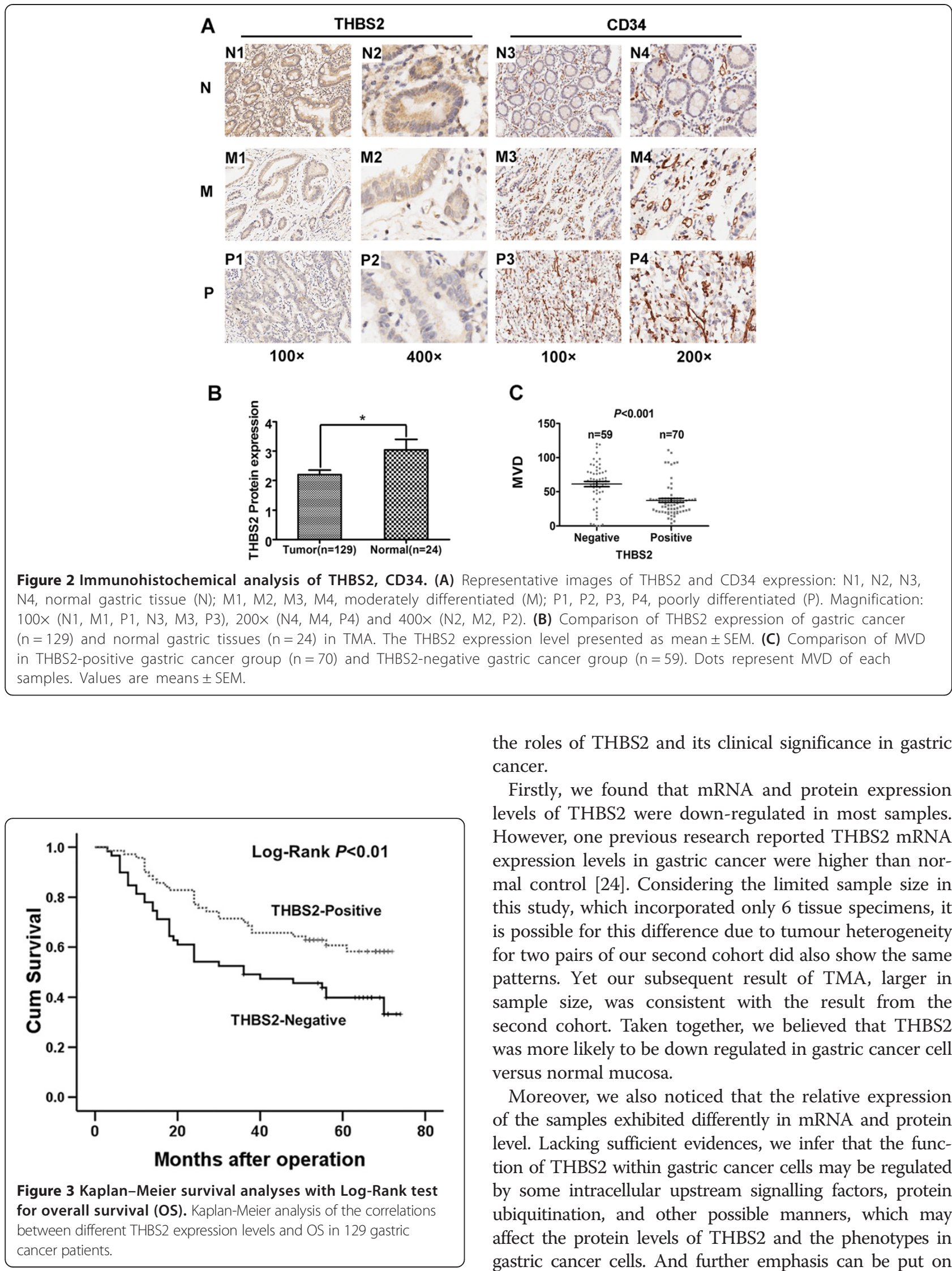

the roles of THBS2 and its clinical significance in gastric cancer.

Firstly, we found that mRNA and protein expression levels of THBS2 were down-regulated in most samples. However, one previous research reported THBS2 mRNA expression levels in gastric cancer were higher than normal control [24]. Considering the limited sample size in this study, which incorporated only 6 tissue specimens, it is possible for this difference due to tumour heterogeneity for two pairs of our second cohort did also show the same patterns. Yet our subsequent result of TMA, larger in sample size, was consistent with the result from the second cohort. Taken together, we believed that THBS2 was more likely to be down regulated in gastric cancer cell versus normal mucosa.

Moreover, we also noticed that the relative expression of the samples exhibited differently in mRNA and protein level. Lacking sufficient evidences, we infer that the function of THBS2 within gastric cancer cells may be regulated by some intracellular upstream signalling factors, protein ubiquitination, and other possible manners, which may affect the protein levels of THBS2 and the phenotypes in gastric cancer cells. And further emphasis can be put on 


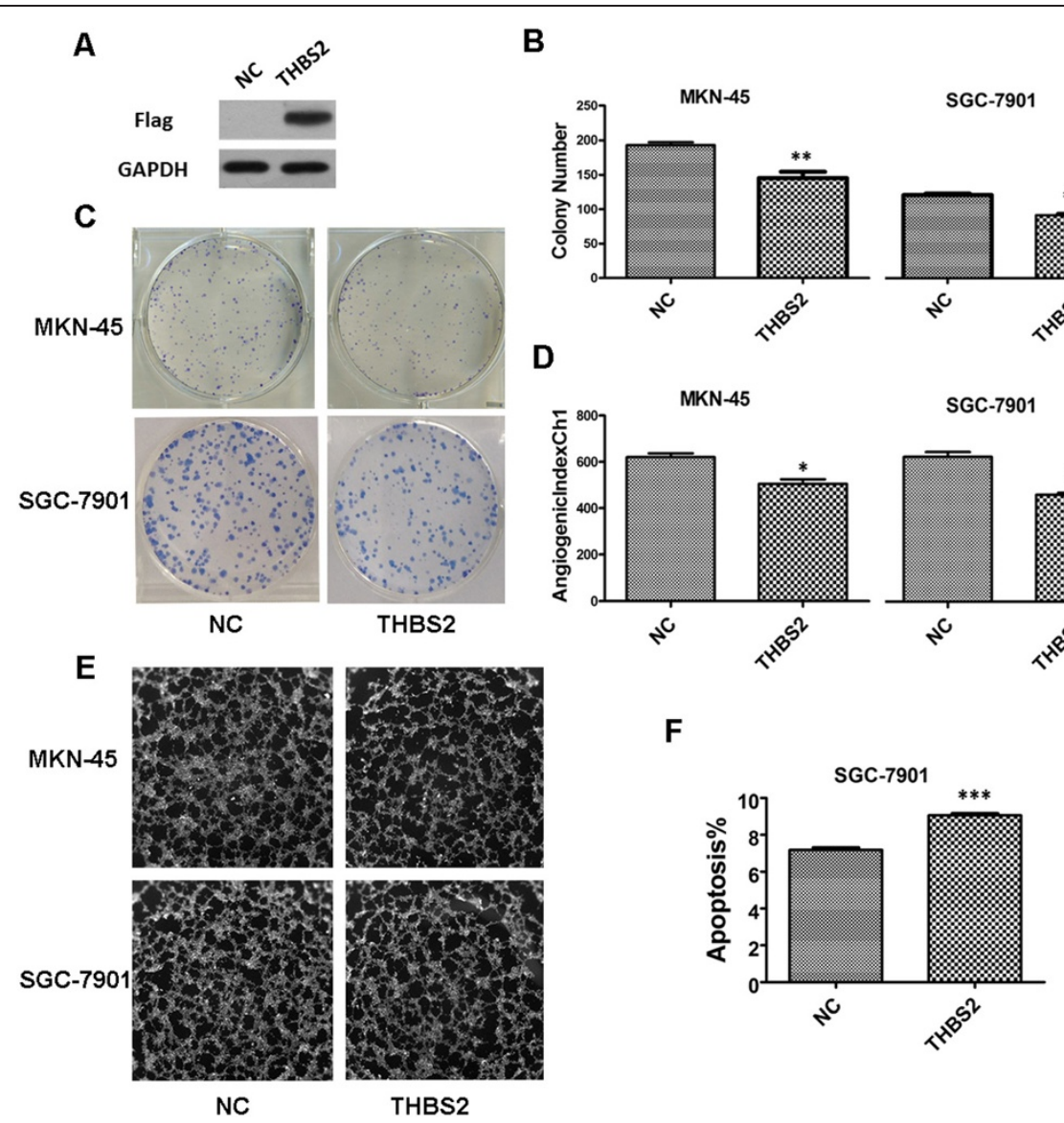

Figure 4 Overexpression of THBS2 inhibited the proliferation of gastric cancer cells, suppressed the angiogenesis of gastric cancer, and promoted apoptosis in SGC-7901 cell line in vitro. (A) Western blot analysis of Flag in 293 T cells with THBS2 overexpression. (B) Colony number analysis for MKN-45 and SGC-7901 cells with THBS2 overexpression and negative control. Values are means \pm SD from three independent experiments. (C) Images of colony formation assay. (D) AngiogenicIndexCh1 analysis of endothelial cell tube formation assay. Values are means \pm SD. (E) Images of endothelial cell tube formation assay. (F) Analysis of apoptosis in MKN-45 cell line. Values are means \pm SD.

this interesting phenomenon. Nevertheless, the majority of the samples from our second cohort displayed the same expression patterns between mRNA and protein levels.

Secondly, our data showed that THBS2 could promote apoptosis only in SGC-7901 cells but not in MKN-45 cells. Former researches showed that an $\mathrm{N}$-terminal recombinant fragment of THBS2 could activate CD36-mediated endothelial cell apoptosis [14], and the combination of CD36 and THBS2 could activate the caspase signalling pathway [25]. Thus, we assumed that the heterogeneity of the two cell lines used in our study, like differentiated CD36 expressions, might partly be the reason of different levels of apoptosis induced by THBS2, which called for further investigations.

Thirdly, our results showed that THBS2 could suppress angiogenesis of gastric cancer. It is known that tumour proliferation, invasion, or metastasis are dependent on angiogenesis [26]. And based evidences support our discovery and point out that the possible mechanisms that THBS2 inhibits angiogenesis: 1) an apoptosis-independent fashion by inducing endothelial cell apoptosis, cell cycle arresting and decreasing of endothelial cell migration [27], 2) dependent on caspase signalling pathway activated by CD36 [28]. 3) functioning as co-receptors for the low density lipoprotein receptor related protein (LRP1), which could clear the complexes of THBS2 with matrix metalloproteinases-2, -9 or vascular endothelial growth factor (VEGF) from the pericellular environment of mesenchymal cells [29-32].

Lastly, MVD is one of the most commonly used parameters to assess the degree of tumour angiogenesis and previous studies have found MVD could be an independent prognostic factor in gastric cancer and other tumour [33-35]. In our study, we found MVD was significantly correlated with THBS2 protein expression $(P<0.001)$ in gastric cancer, but not with clinical features and clinical prognosis. These results demonstrated that THBS2 could affect angiogenesis in gastric cancer, nevertheless, because of no correlation between MVD and prognosis in our samples, we suspected that higher THBS2 expression 
indicating longer survival was not merely through inhibiting angiogenesis of gastric cancer, other mechanisms such as regulating ECM remoulding [23] and proliferation rate of gastric cancer cells might also be the reasons that need further researches to explore.

Collectively, our findings emphasized on the important roles of THBS2 in prognostic significances as well as tumour proliferation and angiogenesis in gastric cancer. These data suggest THBS2 could be an important prognostic marker for gastric cancer patients. Moreover, based on the effects of THBS2 on tumour development and angiogenesis, our researches provide valuable clues for clinical practices to develop molecular inhibiting therapeutics using targets deduced from the biological knowledge provided by the THBS2 signature.

\section{Conclusion}

Our study presents the first line of evidences that THBS2 expression is down-regulated at both mRNA and protein levels and decreased THBS2 expression is associated with the poor histological grade of gastric cancer. Crucially, overexpression of THBS2 has a significant correlation with favourable prognosis of gastric cancer patients. On the other hand, THBS2 affected prognosis in gastric cancer may not only through regulating the angiogenesis, but in some other manners like regulating ECM remoulding and inhibiting the proliferation of gastric cancer cells. These findings suggest that THBS2 could be a potentially critical role of in the pathogenesis and progression of gastric cancer. We confirm that, with the gradual depth studies of THBS2, it may be a promising useful and simple biomarker for predicting clinical outcome for gastric cancer patients.

\section{Methods}

\section{Patients and tissue specimens}

In the present study, we incorporated two cohorts of specimens. The first cohort contained 129 formalin-fixed, paraffin-embedded human gastric cancer and 24 randomly selected normal gastric tissues. They were consecutively recruited between December 2006 and May 2008 from Department of General Surgery, The First Affiliated Hospital of Anhui Medical University, Hefei, China. These specimens were incorporated into TMA for immunohistochemical staining. Histological features of these specimens were confirmed by pathologists. Pathological TNM staging was evaluated according to the 2010 criteria of The American Joint Committee on Cancer (AJCC). The second cohort was composed of 14 gastric cancer patients who undergone tumour resection therapy at the Eighth Department of General Surgery, The First Affiliated Hospital of Anhui Medical University. The fresh gastric cancer tissue and corresponding normal mucosa (at least $5 \mathrm{~cm}$ distant from the tumour edge) were immediately frozen in liquid nitrogen and stored at $-80^{\circ} \mathrm{C}$ until using for Quantitative real-time PCR and Western blot analysis. Patients in both cohorts did not receive preoperative chemotherapy and/or radiation. Written informed consent was provided by all participants. All specimens were handled anonymously according to the ethical standards. This study was conducted with the approval of the Ethical Review Committee of the hospital.

\section{RNA extraction and quantitative real-time PCR}

Total RNA was extracted from the second cohort using Trizol reagent (Invitrogen) according to the manufacturer's protocol. cDNA was synthesized by random primers and Superscript II reverse transcriptase (Toyobo, Osaka, Japan). The primers used for amplification for THBS2: forward primer 5'-CGTGGACAATGACCTTG TTG-3' and reverse primer 5'-GCCATCGTTGTCATC ATCAG-3'. Glyceraldehyde-3-phosphate dehydrogenase (GAPDH) was amplified in the same q-PCR as an internal control using primers: forward primer 5'-AGCCACATC GCTCAGACAC-3' and reverse primer 5'-GCCCAATA CGACCAAATCC-3'. The reaction ran on the ABI 7900HT Sequence Detection System (Applied Biosystems, CA, USA) in the presence of SYBR-Green dye (Toyobo, Osaka, Japan). The reaction condition was a denaturation program $\left(95^{\circ} \mathrm{C}\right.$ for $\left.5 \mathrm{~min}\right)$, and an amplification and quantification program for 40 cycles $\left(95^{\circ} \mathrm{C}\right.$ for $15 \mathrm{~s}$ and $60^{\circ} \mathrm{C}$ for $45 \mathrm{~s})$. Every sample was tested in triplicates, and a melting curve analysis of each sample was used to check the specificity of amplification. The expression level was determined as a ratio between THBS2 and the internal control GAPDH in the amounts of mRNA calculated by comparative CT method.

\section{Protein extraction and Western blot}

Total protein were extracted from 14 frozen gastric cancer and its corresponding normal mucosa tissue by ice in radio immunoprecipitation assay Lysis Buffer (RIPA; Beyotime institute of Biotechnology, Jiangsu, China), and measured using a BCA protein assay kit (Beyotime institute of Biotechnology, Jiangsu, China). The lysate was centrifuged at $12000 \mathrm{rpm}$ for 5 minutes, and the supernatant was heated at $100^{\circ} \mathrm{C}$ for 5 minutes. Then equivalent proteins of each pair specimens were separated on $8 \%$ sodium dodecyl sulfate polyacrylamide gel electrophoresis and electrotransferred to polyvinylidene fluoride membranes (Millipore, Billerica, MA). After The blocked with TBST containing 5\% skim milk in at room temperature for one hour, the membranes were blotted with anti-THBS2 antibody (1:1500; Novus) and anti-Flag (1:3000; Sigma). Followed membranes incubation with horseradish peroxidase-labelled anti-rabbit and anti-mouse IgG as the secondary antibody (Beyotime 
institute of Biotechnology). Anti-GAPDH antibody (1:4000; Aogma) was used as a loading control antibody. The bound antibodies were detected with the enhanced chemiluminescence method.

\section{Immunohistochemistry and TMA analysis}

Gastric cancer and normal gastric mucosa specimens were formalin-fixed, paraffin-embedded and were used to construct a tissue TMA. H\&E-stained slides were screened to identify optimal intratumoural tissue for analysis. 4- $\mu \mathrm{m}$ thick sections were baked at $60^{\circ} \mathrm{C}$ for 1 hour, deparaffinised with xylenes, and rehydrated in graded ethanol to distilled water. Antigen retrieval was achieved with placing the sections with citrate buffer in a rice steamer for 30 minutes. To quench the endogenous peroxidase activity, the sections were treated with $3 \% \mathrm{H}_{2} \mathrm{O}_{2}$ in methanol. Then we used $1 \%$ bovine serum albumin to block the nonspecific binding. Anti-THBS2 antibody (Novus, 1:2000) and anti-CD34 (Abcam, 1:250) were incubated with the sections at $37^{\circ} \mathrm{C}$ overnight, then incubated with horseradish peroxidase-labelled Anti-rabbit IgG as the secondary antibody (Life Technologies). In the end, slides were placed on an autostainer link instrument and proceed with staining. For negative controls, the primary antibodies were replaced with normal rabbit serum. The final effective immunohistochemical staining was evaluated by two independent pathologists without knowing the information of patients according to the staining intensity and extent of staining. Tissue section was scored as the percentage of stained cytoplasm in gastric cancer gland cells and normal gland cells ( 0 points for no cells stained, 1 point for $<25 \%, 2$ points for $25-75 \%$, and 3 points for $>75 \%$ of cells stained), and the staining intensity of immunoreactivity was graded on a scale of 0 to 3 . The immunoreactivity score (IRS) was resulted from the multiplication of both parameters. Specimens were scored as follows: negative (IRS $=0 \sim 2$ ), positive (IRS = $3 \sim 9$ ).

\section{MVD counting}

Immunohistochemical staining of CD34 and generally accepted criteria performed by Weidner et al. [36] were used for MVD counting. Any stained endothelial cells or endothelial cell clusters were separated from adjacent microvessels, and the thickness of every vessel wall over $2.75 \mu \mathrm{m}$ would be excluded. Three separate sections containing hot-spots (where the highest number of discrete microvessels was stained) in each sample of TMA were chosen in low magnifications $(100 \times)$ under a light microscope (Leica, Germany). Subsequently, microvessels were counted in each section in high magnification $(200 \times)$. Final counts were expressed as the average of all the three sections examined.

\section{Cell culture and lentivirus infection}

Gastric adenocarcinoma cell line MKN-45 and SGC-7901 were obtained from the Shanghai Institutes for Biological Sciences, Chinese Academy of Sciences. These two cell lines were grown in RPMI1640 medium (Gibco, USA) supplemented with $10 \%$ fetal bovine serum (FBS, Gibco, USA), and incubated at $37^{\circ} \mathrm{C}$ in a humidified atmosphere with $5 \% \mathrm{CO}_{2}$. The maintenance of MKN-45 and SGC7901 cell lines were described previously [37]. Human 293 T cells were maintained in DMEM with $10 \%$ fetal bovine serum (Gibco, USA). To generate cell lines overexpressing THBS2, the open reading frame of THBS2 [GenBank:NM_003247.3] was cloned into the lentiviral vector GV287 (Ubi-MCS-3FLAG-SV40-EGFP; GeneChem Co., Ltd), and GV287 empty vector served as negative control (NC) for Ubi-THBS2-3FLAG-SV40-EGFP. The procedures of packaging and infection of lentivirus were according to the previous study [38].

\section{Colony formation assay}

Colony formation was performed as described previously $[39,40] .8 \times 10^{2}$ cells suspended in DMEM medium containing $10 \%$ fetal bovine serum were plated in 6-well plates. The plates were incubated at $37^{\circ} \mathrm{C}$ in a $5 \% \mathrm{CO}_{2}$ incubator for 14 days or colonies with more than 50 cells were counted. Each dose was done in triplicate, and the experiments were done at least three times.

\section{Endothelial cell tube formation assay}

The tube formation assay was done as described previously [41]. $70 \mu \mathrm{L}$ of Matrigel Basement Membrane Matrix (BD Biosciences) were pipetted into each well of a 96-well plate and polymerized for 30 minutes at $37^{\circ} \mathrm{C}$. HUVECs were harvested after trypsin treatment and suspended in conditioned medium from THBS2 overexpression group and NC group. Then $2 \times 10^{4}$ HUVECs with these conditioned medium were added to each well and incubated at $37^{\circ} \mathrm{C}, 5 \% \mathrm{CO}_{2}$, for 20 hours. The cultures were stained with Cellomics Cytoskeletal Rearrangement Kits (Thermo Fisher Scientific) according to the protocol by the company and analysed with Cellomics (Thermo Fisher Scientific). The measurement is AngiogenicIndexCh1 which is defined as $1000 \times$ Total Area of Connected Tubes/Total Image Area(Thermo Fisher Scientific provided).

\section{Cell migration assay}

Cell migration assays were examined according to previous study [42]. $1 \times 10^{5}$ cells in $100 \mu \mathrm{L}$ DMEM medium without FBS were seeded on a fibronectin coated polycarbonate membrane insert in a Transwell apparatus (Corning, NY, USA). $600 \mu \mathrm{l}$ DMEM containing 10\% FBS was added into the lower chamber. When the 20 hours incubation was completed, cells were fixed with methanol and stained with Giemsa. Cell numbers on the lower side of the filter 
were counted under a light microscopy (Olympus micropublisher 3.3RTV). Each dose was done in triplicate, and the experiments were done at least three times.

\section{Apoptosis analysis}

Apoptosis analysis was described in detail previously [37]. These assays used apoptosis kit (eBioscince, USA ) following to the manufacturer's instructions. The stained cells were analysed by flow cytometry (FACSCalibur, BD).

\section{Statistical analysis}

SPSS 15.0 software (SPSS, Inc. Chicago) was used for all statistical analyses. Fisher's exact test or The Pearson $\chi^{2}$ test was used to analyse the relationship between THBS2 protein expression level and the clinicopathologic features. Mann-Whitney U test used for comparing MVD with THBS2 expression and clinicopathologic features as well as the protein expression level between gastric cancer tissue and normal tissue in the TMA. Survival curves calculation and OS curve plotting used the KaplanMeier method, and the Log-Rank test was applied to compare the distribution between groups. Multivariate Cox's proportional hazards models were used to explore the effects of the clinicopathologic variables with THBS2 protein expression level on survival. Comparisons of quantitative data were analyzed by Student's t-test between two groups (two-tailed). *, ***, or ${ }^{* * * * *}$ indicates $P<0.05, P<0.01$, or $P<0.001$, respectively. $P<0.05$ was defined as statistically significant.

\section{Additional file}

Additional file 1: Figure S1. Apoptosis analysis of MKN-45 cell line and cell migration assay. (A) Analysis of apoptosis in MKN-45 cell line. Values are means \pm SD. (B) Migration number counted and analysis under 400x microscope. (C) Images of colony migration assay (400X).

\section{Competing interests}

The authors declare that they have no competing interest.

\section{Authors' contributions}

$Y L$ and DL designed research; RS and YC performed the experiments, analyzed the data and wrote the manuscript. JW, ML, SZ selected samples. All authors read and approved the manuscript.

\section{Acknowledgements}

This work was supported by Natural Science Foundation of China (30871207). We further thank all volunteers recruited in this study.

\section{Author details \\ ${ }^{1}$ The Eighth Department of General Surgery, Hefei, China. ${ }^{2}$ Department of Pathology, the First Affiliated Hospital of Anhui Medical University, Hefei, China. ${ }^{3}$ State Key Laboratory of Genetic Engineering, Fudan-VARI Genetic Epidemiology Center and MOE Key Laboratory of Contemporary Anthropology, Fudan University, Shanghai, China.}

Received: 11 December 2013 Accepted: 22 September 2014 Published: 28 September 2014

\section{References}

1. Siegel R, Ma J, Zou Z, Jemal A: Cancer statistics, 2014. CA Cancer J Clin 2014, 64:9-29.

2. Bornstein P: Thrombospondins function as regulators of angiogenesis. J Cell Commun Signal 2009, 3:189-200.

3. Stenina Ol, Topol EJ, Plow EF: Thrombospondins, their polymorphisms, and cardiovascular disease. Arterioscler Thromb Vasc Biol 2007, 27:1886-1894.

4. Adams JC, Lawler J: The thrombospondins. Int J Biochem Cell Biol 2004, 36:961-968

5. Iruela-Arispe ML, Luque A, Lee N: Thrombospondin modules and angiogenesis. Int J Biochem Cell Biol 2004, 36:1070-1078.

6. Lawler PR, Lawler J: Molecular basis for the regulation of angiogenesis by thrombospondin-1 and -2. Cold Spring Harb Perspect Med 2012, 2:a006627.

7. Folkman J: Tumor angiogenesis: therapeutic implications. N Engl J Med 1971, 285:1182-1186.

8. Ferrara N, Kerbel RS: Angiogenesis as a therapeutic target. Nature 2005, 438:967-974.

9. Carmeliet P, Jain RK: Angiogenesis in cancer and other diseases. Nature 2000, 407:249-257.

10. Weidner $\mathrm{N}$ : Current pathologic methods for measuring intratumoral microvessel density within breast carcinoma and other solid tumors. Breast Cancer Res Treat 1995, 36:169-180.

11. Bornstein P, Armstrong LC, Hankenson KD, Kyriakides TR, Yang Z: Thrombospondin 2, a matricellular protein with diverse functions. Matrix Biol 2000, 19:557-568.

12. Tokunaga $T$, Nakamura M, Oshika $Y$, Abe $Y$, Ozeki $Y$, Fukushima $Y$, Hatanaka H, Sadahiro S, Kijima H, Tsuchida T, Yamazaki H, Tamaoki N, Ueyama Y: Thrombospondin 2 expression is correlated with inhibition of angiogenesis and metastasis of colon cancer. Br J Cancer 1999, 79:354-359.

13. De Fraipont F, Nicholson AC, Feige JJ, Van Meir EG: Thrombospondins and tumor angiogenesis. Trends Mol Med 2001, 7:401-407.

14. Koch M, Hussein F, Woeste A, Grundker C, Frontzek K, Emons G, Hawighorst $\mathrm{T}$ : CD36-mediated activation of endothelial cell apoptosis by an $\mathrm{N}$-terminal recombinant fragment of thrombospondin-2 inhibits breast cancer growth and metastasis in vivo. Breast Cancer Res Treat 2011, 128:337-346.

15. Rendtlew Danielsen JM, Knudsen LM, Dahl IM, Lodahl M, Rasmussen T: Dysregulation of CD47 and the ligands thrombospondin 1 and 2 in multiple myeloma. Br J Haematol 2007, 138:756-760.

16. Chijiwa T, Abe Y, Ikoma N, Yamazaki H, Tsukamoto H, Suemizu H, Kawai K, Wakui M, Nishime C, Matsumoto H, Matsuyama M, Mukai M, Ueyama Y, Nakamura M: Thrombospondin 2 inhibits metastasis of human malignant melanoma through microenvironment-modification in NOD/SCID/gammaCnull (NOG) mice. Int J Oncol 2009, 34:5-13.

17. Matos AR, Coutinho-Camillo CM, Thuler LC, Fonseca FP, Soares FA, Silva EA Gimba ER: Expression analysis of thrombospondin 2 in prostate cancer and benign prostatic hyperplasia. Exp Mol Pathol 2013, 94:438-444.

18. Oshika Y, Masuda K, Tokunaga T, Hatanaka H, Kamiya T, Abe Y, Ozeki Y, Kijima H, Yamazaki H, Tamaoki N, Ueyama Y, Nakamura M: Thrombospondin 2 gene expression is correlated with decreased vascularity in non-small cell lung cancer. Clin Cancer Res 1998, 4:1785-1788.

19. Chijiwa T, Abe $Y$, Inoue $Y$, Matsumoto H, Kawai K, Matsuyama M, Miyazaki N, Inoue H, Mukai M, Ueyama Y, Nakamura M: Cancerous, but not stromal, thrombospondin-2 contributes prognosis in pulmonary adenocarcinoma. Oncol Rep 2009, 22:279-283.

20. Nakao T, Kurita N, Komatsu M, Yoshikawa K, Iwata T, Utsunomiya T, Shimada M: Expression of thrombospondin-1 and Ski are prognostic factors in advanced gastric cancer. Int J Clin Oncol 2011, 16:145-152.

21. Forster $S$, Gretschel S, Jons T, Yashiro M, Kemmner W: THBS4, a novel stromal molecule of diffuse-type gastric adenocarcinomas, identified by transcriptome-wide expression profiling. Mod Pathol 2011, 24:1390-1403.

22. Bornstein P, Agah A, Kyriakides TR: The role of thrombospondins 1 and 2 in the regulation of cell-matrix interactions, collagen fibril formation, and the response to injury. Int J Biochem Cell Biol 2004, 36:1115-1125.

23. Krady MM, Zeng J, Yu J, MacLauchlan S, Skokos EA, Tian W, Bornstein P, Sessa WC, Kyriakides TR: Thrombospondin-2 modulates extracellular matrix remodeling during physiological angiogenesis. Am J Pathol 2008, 173:879-891. 
24. Yang S, Shin J, Park KH, Jeung HC, Rha SY, Noh SH, Yang WI, Chung HC: Molecular basis of the differences between normal and tumor tissues of gastric cancer. Biochim Biophys Acta 2007, 1772:1033-1040.

25. Jimenez B, Volpert OV, Crawford SE, Febbraio M, Silverstein RL, Bouck N: Signals leading to apoptosis-dependent inhibition of neovascularization by thrombospondin-1. Nat Med 2000, 6:41-48.

26. Folkman $\mathrm{J}$ : What is the evidence that tumors are angiogenesis dependent? J Natl Cancer Inst 1990, 82:4-6.

27. Armstrong LC, Bjorkblom B, Hankenson KD, Siadak AW, Stiles CE, Bornstein $P$ : Thrombospondin 2 inhibits microvascular endothelial cell proliferation by a caspase-independent mechanism. Mol Biol Cell 2002, 13:1893-1905.

28. Dawson DW, Pearce SF, Zhong R, Silverstein RL, Frazier WA, Bouck NP: CD36 mediates the In vitro inhibitory effects of thrombospondin-1 on endothelial cells. J Cell Biol 1997, 138:707-717.

29. Yang Z, Strickland DK, Bornstein P: Extracellular matrix metalloproteinase 2 levels are regulated by the low density lipoprotein-related scavenger receptor and thrombospondin 2. J Biol Chem 2001, 276:8403-8408.

30. Hahn-Dantona E, Ruiz JF, Bornstein P, Strickland DK: The low density lipoprotein receptor-related protein modulates levels of matrix metalloproteinase 9 (MMP-9) by mediating its cellular catabolism. J Biol Chem 2001, 276:15498-15503.

31. Greenaway J, Lawler J, Moorehead R, Bornstein P, Lamarre J, Petrik J: Thrombospondin-1 inhibits VEGF levels in the ovary directly by binding and internalization via the low density lipoprotein receptor-related protein-1 (LRP-1). J Cell Physiol 2007, 210:807-818.

32. Rodriguez-Manzaneque JC, Lane TF, Ortega MA, Hynes RO, Lawler J Iruela-Arispe ML: Thrombospondin-1 suppresses spontaneous tumor growth and inhibits activation of matrix metalloproteinase- 9 and mobilization of vascular endothelial growth factor. Proc Natl Acad Sci U S A 2001, 98:12485-12490.

33. Weidner $\mathrm{N}$ : Intratumor microvessel density as a prognostic factor in cancer. Am J Pathol 1995, 147:9-19.

34. Chen CN, Cheng YM, Lin MT, Hsieh FJ, Lee PH, Chang KJ: Association of color Doppler vascularity index and microvessel density with survival in patients with gastric cancer. Ann Surg 2002, 235:512-518.

35. Leon SP, Folkerth RD, Black PM: Microvessel density is a prognostic indicator for patients with astroglial brain tumors. Cancer 1996, 77:362-372.

36. Weidner N, Semple JP, Welch WR, Folkman J: Tumor angiogenesis and metastasis-correlation in invasive breast carcinoma. N Engl J Med 1991, 324:1-8.

37. Duan Y, Hu L, Liu B, Yu B, Li J, Yan M, Yu Y, Li C, Su L, Zhu Z, Xiang M, Yang Q: Tumor suppressor miR-24 restrains gastric cancer progression by downregulating RegIV. Mol Cancer 2014, 13:127.

38. Gong F, Peng X, Luo C, Shen G, Zhao C, Zou L, Li L, Sang Y, Zhao Y, Zhao X: Cathepsin $B$ as a potential prognostic and therapeutic marker for human lung squamous cell carcinoma. Mol Cancer 2013, 12:125.

39. Li L, Wang L, Song P, Geng X, Liang X, Zhou M, Wang Y, Chen C, Jia J, Zeng $\mathrm{J}$ : Critical role of histone demethylase RBP2 in human gastric cancer angiogenesis. Mol Cancer 2014, 13:81.

40. Jiang CG, Lv L, Liu FR, Wang ZN, Liu FN, Li YS, Wang CY, Zhang HY, Sun Z, Xu HM: Downregulation of connective tissue growth factor inhibits the growth and invasion of gastric cancer cells and attenuates peritoneal dissemination. Mol Cancer 2011, 10:122.

41. Gong W, Wang L, Yao JC, Ajani JA, Wei D, Aldape KD, Xie K, Sawaya R, Huang S: Expression of activated signal transducer and activator of transcription 3 predicts expression of vascular endothelial growth factor in and angiogenic phenotype of human gastric cancer. Clin Cancer Res 2005, 11:1386-1393.

42. Song Y, Luo Q, Long H, Hu Z, Que T, Zhang X, Li Z, Wang G, Yi L, Liu Z, Fang W, Qi S: Alpha-enolase as a potential cancer prognostic marker promotes cell growth, migration, and invasion in glioma. Mol Cancer 2014, 13:65

\section{doi:10.1186/1476-4598-13-225}

Cite this article as: Sun et al: Down regulation of Thrombospondin2 predicts poor prognosis in patients with gastric cancer. Molecular Cancer 2014 13:225.

\section{Submit your next manuscript to BioMed Central and take full advantage of:}

- Convenient online submission

- Thorough peer review

- No space constraints or color figure charges

- Immediate publication on acceptance

- Inclusion in PubMed, CAS, Scopus and Google Scholar

- Research which is freely available for redistribution 